\title{
PODER POLÍTICO E FAMILIAR NA ALEP: 1947-1962 ${ }^{1}$
}

\author{
Mônica Helena Harrich Silva Goulart²
}

- Enviado em 15/04/2016

- Aprovado em 20/05/2016

\section{RESUMO}

Este texto se constitui de uma análise (em andamento) acerca da concentração de poder e das relações de parentesco na Assembleia Legislativa do Paraná, no período de 1947 a 1962. Tal parlamento é entendido, nesse sentido, como subcampo do campo político paranaense, conforme possibilidades de investigação a partir da perspectiva bourdieusiana. As trajetórias políticas e as biografias dos deputados são relevantes para o entendimento da concentração de poder e das relações de parentesco configuradas no referido espaço. Dicionários e obras biográficas, textos sobre poder legislativo e política do Paraná, além de sites oficiais e específicos, são utilizados como fontes importantes para a pesquisa.

Palavras-chave: ALEP. Política Paranaense. Família.

\section{A ALEP COMO OBJETO DE ESTUDO}

O presente estudo faz parte do projeto de pesquisa que almeja dar continuidade às análises sobre a Assembleia Legislativa do Paraná, desenvolvido no programa de Doutorado, Sociologia pela UFPR - Tese Classe Dominante e Jogo Político na Assembleia Legislativa Paranaense (1889-1930). (GOULART, 2008). Os dados apresentados englobam especificamente as legislaturas ${ }^{3}$ entre o período do pós Estado Novo e os anos anteriores à Ditadura Militar, ou seja, abrange os mandatos de 1947-1950, 1951-1954, 1955-1958 e 1959-1962. De forma geral, pretende-se estender

\footnotetext{
${ }^{1}$ Uma versão preliminar desse trabalho foi apresentada no GT1: INSTITUIÇÕES E PODER: PARENTESCOS E GENEALOGIAS do VII Seminário Nacional de Sociologia e Política da UFPR realizado de 11 a 13 de maio de 2016 em Curitiba.
}

${ }^{2}$ Doutora em Sociologia - UFPR. Professora Adjunta na Universidade Tecnológica Federal do Paraná (UTFPR) Departamento Acadêmico de Estudos Sociais (DAESO). Endereço eletrônico: mharrich@uol.com.br

3 Optamos em delimitar o período de análise com a $4^{\mathrm{a}}$ Legislatura porque a $5^{\mathrm{a}}$ Legislatura e o perfil de seus parlamentares já foram esmiuçados no trabalho de Mestrado de Natália Cristina Granato (2016), além do fato de que este período parlamentar é "cortado" pelo Golpe de 1964, implicando mudanças profundas na dinâmica parlamentar. Fato que merece análise específica, como realizada pela pesquisadora mencionada. 
a análise já realizada do legislativo estadual da República Velha com o intuito de detectar continuidades e rupturas no que diz respeito ao processo parlamentar, à dinâmica político partidária estadual e, sobretudo, nesse caso, os aspectos que indicam o perfil do corpo parlamentar e suas relações familiares.

Tal conjuntura se constitui de um conjunto formado por 126 deputados $^{4}$ e, destes, estamos incluindo também os suplentes que exerceram seus mandatos mesmo em curtos períodos, mas que de alguma forma também participaram do jogo político. Este cenário é inaugurado pela Constituinte do Paraná de 1947, a qual instituiu a composição de 37 deputados para o parlamento estadual, com duração de quatro anos para cada período legislativo, funcionando as sessões a partir do dia $1^{\circ}$ de maio até o dia 30 de setembro ${ }^{5}$. Já a partir da legislatura de 1951, o número de cadeiras foi ampliado para 45 .

Scott P. Mainwaring (2001) indica que a concentração de estudos sobre o poder legislativo e seus aspectos políticos remonta ao período marcado pela terceira onda de democratização, ou seja, compreende o final da década de 70. Porém, as análises direcionadas ao papel do legislativo no Brasil convergem a partir dos anos 90, momento em que as pesquisas sobre o legislativo nacional se intensificam, assim como os estudos sobre o poder nas unidades subnacionais passam a ser objeto de vários estudos.

Vale ressaltar que mesmo num período social, político e econômico diferenciado em relação à ALEP da República Velha, entendemos que o referido parlamento continua se colocando como instituição fundamental para compreensão da dinâmica política do Paraná. Dessa forma, a ALEP continua sendo entendida como subcampo do campo político paranaense, conforme definição de Pierre Bourdieu. Assim como teve papel fundamental para organização do campo político paranaense no período anterior ${ }^{6}$, a ALEP como subcampo continuou representando alianças temporárias e inflexíveis, bem como os acordos e conflitos internos da classe dominante. Portanto,

\footnotetext{
${ }^{4}$ Alguns suplentes foram detectados somente no decorrer da pesquisa com os Anais da ALEP, portanto, não foram considerados para o presente trabalho. Do total deputados do período, $108(85,71 \%)$ tiveram seus mandatos políticos somente dentro do período abordado, seis (4,76\%) deputados também ocuparam cadeira no período de $1935-1937$ e 12 $(9,52 \%)$ estenderam seus trabalhos parlamentares para além de 1962. (IPARDES, 1987; NÍCOLAS, 1984).
}

5 A Assembleia poderia fixar sessão extraordinária, mas somente por meio de convocação do governador ou por iniciativa de um terço de seus parlamentares, conforme indicação de parágrafo único do artigo 16. (CONSTITUIÇÃ̃), 1947)

\footnotetext{
${ }^{6}$ Formada fundamentalmente por representantes do setor ervateiro (comércio) e por indivíduos vinculados à grande propriedade (pecuária). (GOULART, 2014).
} 
entende-se que a instituição configurada no pós 30 e, de forma precisa, no cenário democrático e pluripartidário (BATISTELLA, 2015) de 1947-1962 se projetou também como espaço político relevante e até mesmo chave para compreensão do campo político estadual.

Da mesma forma, tal locus é compreendido como instituição política capaz de dar continuidade a certos grupos políticos anteriores ${ }^{7}$ e, ao mesmo tempo, absorver novos atores políticos dos pós 1945. Conquanto, conjugou novas forças e interesses em seu espaço a partir de vínculos familiares consolidados no primeiro período republicano (OLIVEIRA, 2004).

Portanto, o objetivo geral do presente texto é sinalizar "quem" ocupou o parlamento estadual através de informações advindas de documentos variados, que informam noções relevantes sobre o grupo. Ao se conhecer o perfil dos parlamentares e suas relações de parentesco, pode-se demarcar como se estabeleceu a dinâmica do jogo uma vez que os deputados se articulam em meio aos seus interesses de grupo (partidários) como também familiares. Daí considerarmos a análise das relações de parentesco como parte essencial da compreensão das instituições políticas brasileiras não só do passado, ainda que remoto, mas também do contexto político contemporâneo.

No que diz respeito à concepção teórica da ALEP como subcampo, este conceito indica um espaço demarcado por configuração de forças, resultando em um locus de concentração de disputas políticas e de diversos interesses. Portanto, tal subcampo, fundamentalmente, é caracterizado por incorporar agentes políticos com diferentes espécies de capital $^{8}$ e de níveis de poder desiguais.

Ao observar a dinâmica de um campo ou subcampo, Bourdieu enfatiza que níveis desiguais de poder resultam em estratégias legais para a permanência das posições dominantes ocupadas por seus agentes. No caso da ALEP, evidencia-se que essas posições acabam por beneficiar determinados agentes em detrimento de outros, que não dispõem das mesmas condições, sejam elas materiais ou simbólicas. Como aspectos materiais compreendemos os recursos econômicos que se colocam como fundamentais para sobrevivência do agente e, nesse caso, são identificados pela ocupação/profissão exercida pelo parlamentar, mas também está relacionado ao patrimônio financeiro da família, além da força política simbólica legitimada pelos sobrenomes que demarcam longa duração no campo político paranaense.

Assim, infere-se que a ALEP como subcampo se estabelece a partir de um jogo onde seus agentes se comportam de forma peculiar, isto é, participam do jogo para manter exatamente suas

\footnotetext{
${ }^{7}$ Conforme aponta Ricardo Costa de Oliveira (2004, p. 18), o “...perfil de algumas novas autoridades nomeadas pela Revolução de 1930 na região atestam a continuidade de tradicionais grupos e famílias no poder.”

${ }^{8}$ O capital (assim como o capital político), segundo Bourdieu, é entendido como uma forma de capital simbólico, crédito firmado na crença e no reconhecimento ou, mais precisamente, nas inúmeras operações de crédito pelas quais os agentes conferem a uma pessoa (ou a um objeto) os próprios poderes que eles lhes reconhecem. (2002, p. 187-188)
} 
posições de poder ou, então, participam do jogo para continuarem no próprio jogo, ainda que apresentem capital político e econômico restritos. Em se tratando especificamente do campo político, Bourdieu (2002, p. 164) o define a partir de sua lógica interna, ou seja, segundo o que este campo produz uma vez que o que se gera são “[...]produtos políticos, problemas, programas, análises, comentários, conceitos, acontecimentos, entre os quais os cidadãos comuns, reduzidos ao estatuto de 'consumidores', devem escolher, com probabilidades de mal-entendimento [sic] tanto maiores quanto mais afastados estão do lugar de produção."

Entender a Assembleia Legislativa paranaense como subcampo do campo político é vê-la como espaço político específico, como um universo particular, tendo suas próprias leis e estrutura de funcionamento, onde os agentes membros da classe dominante dispõem de forças específicas e diferenciadas em relação aos demais, concorrem entre si, estabelecem acordos, produzem fatos (projetos, leis, vetos...), tomam decisões, concedem benefícios e engendram obstáculos políticos aos seus oponentes.

Segundo P. Bourdieu, o conceito de campo tem como função “[...].designar esse espaço relativamente autônomo, esse microcosmo dotado de suas leis próprias.” (BOURDIEU, 2004, p. 20). No caso da ALEP, é uma instituição também fundada em regras próprias (enquanto poder legislativo em geral, e como unidade subnacional específica) para atuação dos agentes políticos, os quais precisam estar cientes de seus capitais e posições para disputarem o jogo. Por serem produzidas em um espaço onde as disputas ocorrem a partir de níveis de capital político diferenciados, suas regras apontam a noção de que a própria distribuição de capital ocorre desigualmente.

A importância do parlamento estadual como subcampo político também está na capacidade de refratar o universo político mais amplo ao qual o estado do Paraná também se encontra influenciado. Afinal, tanto o subcampo (ALEP) quanto o campo político (entendido também a partir do conjunto de outros subcampos como o poder executivo, os partidos políticos, os sindicatos...) possuem interesses e possibilidades de ações onde seus agentes não poderiam coexistir e interagir em outras dimensões do mundo real, daí o fato da construção teórica de campo e subcampo se remeter à condições fundamentais para investigação de determinados grupos sociais, políticos e econômicos, assegurados em seus interesses particulares e em suas posições efetivas.

No que diz respeito ao conceito de jogo, pode-se entende-lo mediante a dinâmica política resultante das ações dos e entre os atores que ocupam as cadeiras de deputados estaduais na 
Assembleia Legislativa de 1947-1962. Afinal, para que o embate político e as disputas de poder se estabeleçam na ALEP, é necessário que os agentes estejam disponíveis a participar de tais disputas, favorecendo alguns e excluindo outros ${ }^{9}$.

Na perspectiva bourdieusiana, os agentes políticos participam do jogo sabendo efetivamente qual capital político dispõem e, assim, agem de acordo com as regras estabelecidas com o intuito de aumentar seu capital (ou capitais) e, ao mínimo, permanecer com o capital detinham antes de adentrar ao subcampo. Nesse ponto, este mecanismo se coloca como relevante para a aludida reflexão, pois pode revelar quais são as regras pré-estabelecidas, as principais práticas interiorizadas pelos políticos presentes no subcampo. Abre-se perspectivas para se pensar quais seriam os capitais relevantes para participação do jogo na referida instituição; fato que reafirma a importância de levantar o perfil dos deputados, os vínculos familiares, a faixa etária, a formação acadêmica, os recursos econômicos, como também o cargo de entrada para o campo político, por exemplo.

Ainda no que diz respeito ao conceito de capital político, Pierre Bourdieu (2004, p.188) revela que este "[...]é uma forma de capital simbólico, crédito firmado na crença e no reconhecimento ou, mais precisamente, nas inúmeras operações de crédito pelas quais os agentes conferem a uma pessoa - ou a um objeto - os próprios poderes que eles lhes reconhecem.”

Para se produzir a análise bourdieusiana sobre a condução da política realizada na ALEP de 1947/1962, torna-se relevante detectar quais seriam os comportamentos, ou melhor, as competências e habilidades dos agentes necessárias para condução do jogo político. Neste caso, os aspectos levantados por meio do perfil parlamentar são indicativos para se engendrar os recursos politicamente necessários, os capitais, para fazer parte do jogo e, mais ainda, podem contribuir na visualização das posições dos atores no interior do subcampo, como também as condições para participação em outros espaços, como o executivo estadual, o secretariado de governo e até mesmo a representação paranaense no senado e na câmara federal.

Os aspectos intrínsecos aos agentes, chamados por Boudieu de habitus, permitem manter suas posições e garantir, assim, os seus interesses no jogo, ainda que diante de situações políticas inesperadas. (BOURDIEU, 2004). Este comportamento deve ser percebido pelo seu sentido ativo, pelo fato de que cada ação traz consigo o habitus, tornando o que era um ato individual, uma ação

\footnotetext{
${ }^{9}$ Importante destacar que os deputados da ALEP de 1947/1962 estavam subdivididos em 8 Partidos Políticos distintos: o Partido Social Democrático - PSD; o Partido Trabalhista Brasileiro - PTB; a União Democrática Nacional - UDN; o Partido Social Progressista - PSP; o Partido Republicano Progressista - PRP; o Partido Republicano - PR; o Partido Democrata Cristão - PDC; o Partido Trabalhista Nacional - PTN. (NÍCOLAS, 1984; COSTA, 1995).
} 
coletiva. O habitus também permite compreender a identidade e o sentido de grupo, tendo em vista que este só pode ser produzido e interiorizado de forma coletiva. Nesse caso, muito do que o parlamentar expressa no jogo pode ser compreendido em meio aos seus vínculos, sejam eles econômicos, intelectuais, sociais e familiares.

A questão levantada por Bourdieu, mediante o conceito de habitus, promove uma visão mais clara da ação dos agentes no interior do subcampo, por conta de que suas atitudes fazem parte de uma estratégia política maior (de grupo) e que deve, obrigatoriamente, ser levada em consideração para que o agente garanta sua própria permanência no jogo.

No que tange ao o conceito de illusio, Bourdieu "[...]procura ressaltar que os interesses específicos surgidos na dinâmica do funcionamento de um campo produzem atores dotados de um sistema de disposições relativamente ajustado a esse espaço social, sendo que a percepção dos interesses em jogo e a perseguição destes se diferenciam em função da posição ocupada no interior desse espaço social.” (MARTINS, 1992, p. 181). Dessa forma, pode-se compreender a diversidade de interesses e o próprio conflito estabelecido no interior da Assembleia Paranaense. Outro aspecto fundamental é perceber a capacidade dos agentes em assegurar seus interesses pelas posições que ocupam no interior do jogo.

\section{FAMÍLIA E PODER: bases dojogo político na ALEP}

Conforme evidencia Ricardo Costa de Oliveira (2012), a partir de análises históricas e contemporâneas da política e relações de poder no Paraná, existe expressiva e recorrente presença de conexões familiares nas mais diversas instituições políticas e administrativas do estado. Para o autor, a presença de determinados sobrenomes remonta desde a época em que as "futuras terras paranaenses" ainda pertenciam à Portugal. (OLIVEIRA, 2001).

Essa abordagem sinaliza uma perspectiva de longa duração, pois, segundo Oliveira (2012), os grupos mais importantes que dominam ${ }^{10}$ atualmente a política estadual através da atuação em

\footnotetext{
${ }^{10}$ Segundo o autor, no ano de 2012 foi possível identificar cerca de apenas 62 famílias detentoras dos cargos públicos mais importantes no Estado, ambientadas em instâncias do Legislativo, do Judiciário, do Executivo, do Ministério Público e do Tribunal de Contas. Esses ramos familiares, além da presença histórica de alguns, compõem o quadro efetivo de detém o poder no estado. (OLIVEIRA, 2012)
} 
diversos cargos (comissionados ou não) são vinculados às famílias que consolidaram seu poder político ao longo de três séculos. (OLIVEIRA, 2012).

Cabe, nesse sentido, indagações a respeito de um cenário mais amplo a respeito do panorama teórico e metodológico sobre a presente discussão: família e política. Portanto, verifica-se nessa análise um distanciamento de foco em relação aos estudos e pesquisas que focalizam suas investigações a partir das relações de mandonismo e de coronelismo, propícias às compreensões de contextos patrimonialistas com instituições de padrões ainda arcaicos e personalistas, delimitadas à época da colonização e do Império, bem como ao contexto da República Velha.

Em que pese as especificidades locais e temporais, o viés do tipo de estudo mencionado anteriormente se pauta por análises empíricas da organização política recorrendo a levantamentos sobre famílias e poderosos locais que detiveram, durante determinado período histórico, poder concentrado em suas mãos, ainda que fosse dividido entre famílias e bravamente disputado entre os diversos grupos. Porém, a presente abordagem direciona a análise para o campo político institucionalizado, a ALEP entre os anos 1947 e 1962. Cenário caracterizado por relações de poder complexas que se materializam no interior de uma instituição racional, num contexto em que a modernização, o capitalismo e a urbanização se encontram plenamente consolidados.

Embora ressaltadas suas críticas e limitações enfatizadas por vários autores da Sociologia, História e até Ciência Política, as obras de Gilberto Freyre (2013), Oliveira Vianna (1987) e Sérgio Buarque de Holanda (1995), formuladas nas décadas de 20 e 30, são referências significativas ao revelar a importância da família como componente fundamental na compreensão da estrutura social brasileira, apontando suas influências e centralidade na construção das relações sociais, sobretudo na esfera política.

Segundo observa Letícia Bicalho Canêdo (1994), a partir dos anos 50 houve um processo de modificação nos estudos sobre política brasileira, não mais com a variável família para compreensão da realidade. O foco passou a ser as questões partidárias (e suas siglas) analiticamente apreendidas por meio de abordagens estatísticas, onde o sobrenome e a presença de grupos familiares deixaram de ter relevância enquanto elementos significativos para apreensão do embate político institucional no contexto democrático.

Para Canêdo, “[...]desprezaram qualquer possibilidade de ver, na tentativa de legitimação e consolidação dos partidos (ou na dificuldade para consolidação deles), a ação de reativar o enraizamentos locais e as filiações ancestrais, como na prática acontecia." (CANÊDO, 1994). Como se a conexão entre família e política não fosse mais percebida no mundo social, visto que o reconhecimento sociológico da não separação entre as esferas pública e privada pudesse acarretar 
contradição à análise da realidade dada. Ou seja, ocorreu um processo de identificação imediata entre política e os jogos partidários, assim como entre o arranjo formal das instituições e o entendimento tão somente estatístico das eleições. (CANÊDO, 2005). Daí o fato do tema família ser redirecionado e apreendido enquanto categoria de intervenção de políticas públicas e retomado em discussões na área de Assistência Social, Direito, Psicologia (Social) e também por meio de estudos da Antropologia, mais notadamente na Antropologia da Política ou, então, próximos das análises do poder local e suas instituições marcadamente atrasadas, conforme já indicado.

A racionalização, burocratização e modernização do campo político não suprimiu a presença de famílias dominando a política nas mais diferentes esferas de poder, tão menos nos aparelhos da administração Estatal, assim como também orientando a ação e o rumo de partidos políticos nos estados. Nesse sentido, Oliveira (2012) chama a atenção para o processo de metamorfose ao qual os grupos dominantes, configurados em famílias e nas relações de parentesco, realizaram ao longo do tempo. Afinal, foram capazes de se manter no poder em meio aos processos de mudança da sociedade brasileira e do aprimoramento de suas inúmeras instituições.

Entretanto, nos anos 90 iniciou-se, por parte de alguns pesquisadores ${ }^{11}$, um processo de retomada analítica do vínculo família e política em estudos que tinham como foco a análise da estrutura e relações de poder, de análise da composição e do perfil dos agentes que compõem instituições públicas e órgãos político administrativos, bem como na reflexão em torno da elevada reprodução política de determinados grupos sociais em cargos eletivos e de nomeação ao longo do tempo, delimitados em famílias (sobrenomes), nas mais variadas esferas do Estado.

Segundo Oliveira (2012) e Canêdo (1994), a genealogia se apresenta no jogo político como mais um elemento para acúmulo de capital simbólico. Sua força passa a ser revelada na medida em que os grupos fazem uso da tradição familiar na política, se valem dos benefícios que o sobrenome trouxe até mesmo para o ingresso no referido campo.

No que tange à esfera da família propriamente dita, o casamento ${ }^{12}$ se revela como ponto chave para garantir a força e a longa duração do sobrenome no campo político, haja vista que ordena a regularidade nas escolhas matrimoniais e define a identidade do grupo. Para a autora, o

11 É, portanto, no contexto da década de 90, mais precisamente em 1996, que é criado e institucionalizado o grupo NEP - Núcleo de Estudos Paranaenses -, que visa em suas investigações a análise das relações de parentesco e de nepotismo na política estadual. Conferir: https://nucleodeestudosparanaenses.wordpress.com/about/.

12 Canêdo realiza o levantamento da trajetória política da família Honório através da duração histórica de aproximadamente 150 anos e do vínculo decorrente de sua matriarca Balbina Honório (casada com Manoel da Silva Canêdo e irmã de Honório Hermeto Carneiro Leão - marquês do Paraná). Os casamentos do grupo seguiram uma lógica de escolhas de candidatos que eram "arregimentados" com membros de famílias de comerciantes e de ocupantes de cargos públicos e políticos. (CANÊDO, 2011). 
casamento se coloca como trunfo importante no jogo político uma vez que acumula capital simbólico e também pode ser fonte de transferência de poder. (CANÊDO, 2011).

Canêdo (1997) também dá ênfase ao fato de que o pertencimento a uma rede de parentesco é apenas uma das potencialidades colocadas em cheque na competição do jogo político. Nesse caso, é preciso considerar outras práticas que se colocam durante a seleção das candidaturas, mas não deixa de considerar as redes políticas; reafirmando a importância de um diálogo permanente e de complementaridade entre História, Sociologia e Ciência Política.

Outra análise contemporânea relevante, que considera a conexão entre família e política, é de Igor Gastal Grill (2012). Nesse sentido, ultrapassa a perspectiva alusiva de que este vínculo (família e política) só pode ser estabelecido em contextos em que as instituições são ineficazes e pouco comprometidas com sua essência efetivamente pública, ou onde os vínculos de parentesco são traços residuais e arcaicos, provenientes de alguns poucos lugares e regiões ainda isoladas e oligárquicas.

Ao observar o cenário político partidário do Rio Grande do Sul e as transformações sociais decorrentes de mudanças econômicas do século XX, Grill indica a conexão entre política e família por meio de suas atuações e movimentos no campo político. Segundo o autor, as siglas partidárias promovem a conexão das famílias políticas na história do estado ao mesmo tempo em que equacionam as diferenças ideológicas, profissionais e ocupacionais mais contundentes no que diz respeito aos grupos políticos.

No presente estudo, que compreende o total de 126 parlamentares da ALEP nas quatro legislaturas entre 1947 a 1962, identificou-se que 53 deputados possuíam vínculos familiares com políticos paranaenses que já haviam ocupado ou estavam ocupando cargos de prefeitos, deputados estaduais e federais, vereadores, senadores e até mesmo ex-governadores. Aspecto que corresponde um conjunto de $42,06 \%$ de deputados da ALEP com conexões familiares.

Mas, no que diz respeito especificamente ao subcampo da ALEP, dos 53 deputados ligados à laços familiares com políticos, 36 possuem parentes que ocuparam cargos antes e/ou após seus respectivos mandatos. Assim, destes, 21 deputados estão vinculados com políticos que também foram membros do parlamento estadual entre os anos 1889-1930, sendo que em alguns casos mais de um familiar esteve presente na ALEP durante este período. Dessa forma, para ilustrarmos deputados estaduais com vínculos de parentesco de membros da ALEP durante a República Velha, pode-se destacar: 
Iraci Ribeiro Vianna, PSD, médico, foi prefeito de Palmas: -Filho de Bernardo Ribeiro Vianna, prefeito de Palmas por duas vezes (1935-1938, 1947-1951) e deputado estadual (19041905, 1906-1907);

-Neto de João Manoel Ribeiro Vianna, vereador em Antonina e deputado estadual (1891-1892);

Lincoln Ferreira da Cunha Pereira, PSP, advogado, foi secretário do Trabalho e Assistência Social: -Neto materno de João Cândido Ferreira, deputado estadual (1897-1898 e 1899), vice-governador (1904-1907) e governador (1908) na República Velha; -irmão de Francisco da Cunha Pereira Filho (jornalista e Diretor/Presidente da RPC - Rede Paranaense de Comunicação); -Sobrinho neto de Victor Ferreira do Amaral e Silva, médico, deputado estadual (1892, 1906-1907), deputado federal (1906-1908), vice-governador (1900-1904) e fundador da Universidade do Paraná; -Sobrinho neto do Secretário de Negócios do Interior, Justiça e Instrução (1900-1903) Octávio Ferreira do Amaral e Silva, também deputado estadual (1894-1895); Sobrinho materno de Alceu Ferreira, deputado estadual (1935-1937); - Sobrinho neto de Joaquim Ferreira do Amaral e Silva, prefeito de Rio Negro; -Sobrinho neto de José Ferreira do Amaral, deputado estadual (1902-1903, 1904-1905, 1908-1909);

Alvir Riesemberg, UDN, médico: -Irmão de Mário Riesemberg, foi prefeito de União da Vitória; -Parente materno do cel. Nicolau Mader, ervateiro, grande proprietário e deputado estadual (1908-1909, 1914-1915, 1916-1917, 1918-1919, 1920-1921);

Já o vínculo de deputados com parentes em cadeiras na ALEP (concentradas) após 1935 corresponde a 10, pois ocuparam cargos da legislatura de 1935 em diante. Nesse caso, pode-se citar os seguintes exemplos:

Antonio Anibeli, PTB, fazendeiro, promotor público, foi prefeito de Clevelândia e deputado federal: -Sogro de Manoel Lustosa Martins, fazendeiro e prefeito de Clevelândia; Cunhado de Cândido Machado de Oliveira Neto, deputado estadual (1951-1954, 1955-1958, 19591962); - Pai de Antonio Martins Anibelli, deputado estadual por sete vezes (1983-1986, 1987-1990, 1991-1994, 1995-1998, 1999-2002, 2003-2006, 2007-2010) e deputado federal (1975-1978, 19791982); -Tio de Luis Alberto Martins de Oliveira, deputado estadual (1975-1978, 1979-1982 ARENA e 1983-1986, 1987-1990 PDS) e senador (1995-1996); -Avô de Antonio Anibelli Neto, deputado estadual (2011-2014, 2015-2018 PMDB);

Miguel Buffara, PTB, advogado, comerciante e deputado federal: -Irmão de Nelson Buffara, vereador de Paranaguá (1952-1955, 1955-1959, 1960-1964, 1964-1968) e deputado estadual (1967-1970, 1971-1974, 1975-1978, 1979-1982, 1983-1986). 
Vidal Vanhoni, PSD, professor, foi secretário da Educação: -Pai de Angelo Vanhoni, vereador (1989-1992 e 1993-1996), deputado estadual (1995-1998, 1999-2002, 2003-2006) e deputado federal (2007-2010, 2011-2015);

Ainda assim, dos 36 parlamentares com parentes na ALEP, 5 deputados possuem relações de parentesco com membros que tiveram cargos parlamentares na República Velha e após 1930. Como exemplo de deputados com vínculos familiares de longa duração na ALEP, tem-se, entre outros:

Nilson de Jesus Baptista, UDN, médico, fazendeiro, foi secretário dos Negócios da Educação e Cultura: -Filho do Cel. Rutílio de Sá Baptista Ribas, fazendeiro, deputado estadual (1920-1921, 1922-1923) e prefeito de Palmas; -Parente materno do Interventor Manoel Ferreira Ribas (1932-1935), prefeito em Santa Maria no Rio Grande do Sul; -Parente paterno de Pretextado Pennaforte Taborda Ribas, deputado estadual (1924-1925, 1926-1927), primeiro Presidente do Banestado e genro do ex-governador José Pereira dos santos Andrade (1896-1900); -Parente paterno de João Lourenço Taborda Ribas, deputado estadual (1902-1903, 1904-1905, 1906-1907, 1908-1909) e camarista em Curitiba; -Parente de Fernando Ribas Carli Filho, eleito deputado estadual em 2006) e de seu irmão Bernardo Ribas Carli, eleito deputado estadual em 2010; ambos também vinculados à família Guimarães por parte de mãe - Ana Rita Slaviero Guimarães (filha de Leoni Slaviero e de Plauto Miró Guimarães), casada com Luiz Fernando Ribas Carli.

Cândido Machado de Oliveira Neto, PSD, promotor público: -Pai de Luis Alberto Martins de Oliveira, deputado estadual (1975-1978, 1979-1982, 1983-1986, 1987-1990) e senador (1991-1995, 1995-1999); -Filho de João Cândido de Oliveira, negociante, coronel e delegado de polícia, deputado estadual (1912-1913, 1930-1931) e prefeito de Tamandaré; -Cunhado de Antonio Anibelli, deputado estadual (1951-1954, 1955-1958, 1959-1962, 1966-1969, 1970-1974).

Paulo Afonso Alves de Camargo, PR, médico e professor: -Filho de Affonso Alves de Camargo, deputado estadual (1897-1898, 1899, 1900-1901, 1906-1907, 1914-1915 PR e PRPr), senador (1922-1928), deputado federal (1921-1923) e governador do Paraná (1916-1920, 19281930); -Irmão de Mário Afonso Alves de Camargo, vereador em Curitiba (1952-1955), prefeito interino de Curitiba (1952); -Tio de Afonso Alves de Camargo Neto, senador (1979-1985 e 19861995), deputado federal (1987-1988, 1995 e Ministro dos Transportes (nas Presidências de Sarney 1985-1986 e Collor 1992); -Cunhado de Bento Munhoz da Rocha Neto, governador do Paraná (1951-1955); -Sobrinho paterno de Marins Camargo (Secretário do Governo do Paraná de Três Pastas), deputado estadual (1910-1911, 1918-1919, 1920-1921), senador (1928-1930); vicegovernador (1924-1928); -Sobrinho materno do cel. José Pinto Rebello Junior, deputado estadual 
(1922-1923, 1924-1925, 1926-1927) e Secretário do Interior, Justiça e Instrução Pública (19281930).

Rivadávia Barbosa Vargas, UDN, comerciante e industrial, foi Secretário de Viação e Obras Públicas: -Pai de Túlio Vargas, escritor e Secretário de Justiça (1975-1979), deputado estadual (1963-1967) e deputado federal (1971-1975, 1975-1979; -Sua esposa, Dalila Rolim Vargas é neta do cel. Telêmaco Borba, deputado estadual (1891-1892, 1897-1898,1899, 1908-1909, 19201911, 1912-1913, 1914-1915) e é também sobrinha de Rogério Borba, deputado estadual (19201921);

\section{TRAÇOS DO PERFIL PARLAMENTAR DA ALEP 1947-1962}

$\mathrm{Na}$ tentativa de levantar aspectos gerais do perfil parlamentar dos deputados estaduais que exerceram atividades na ALEP durante as quatro legislaturas do período de 1947 até 1962, utilizarse-á como principal recurso a prosopografia. Em linhas gerais e conforme destaca Laurence Stone, a prosopografia “[...] é a investigação das características comuns de um grupo de atores por meio de um estudo coletivo de suas vidas." (STONE, 2011, p. 115).

A busca de informações biográficas para compor dados fundamentais dos deputados da ALEP desde 1947 torna-se relevante para a composição de um perfil no qual se indique o próprio habitus do referido grupo. Segundo Stone (2011), ao se levantar informações específicas de um conjunto de atores sociais por meio das biografias coletivas, pode-se identificar a própria realidade social ao mesmo tempo em que também se dá sentido à ação desses indivíduos.

A perspectiva de análise prosopográfica não é recente. Demarcam-se duas escolas iniciais, ambas estabelecidas no período de 1920 a 1930, que contribuíram para o desenvolvimento da prosopografia: de um lado a escola elitista, direcionada aos estudos de grupos restritos, àqueles que se encontram realmente no poder. Nesse caso, os aspectos estatísticos não se colocam como elementos maiores na análise, embora sejam recursos importantes. De outro lado, o direcionamento voltado para os estudos das massas, cuja preocupação fundante encontra-se nas correlações estatísticas, além do foco na história social. Aqui os trabalhos também se referem à mobilidade social dos grupos, além do número maior de questões e do elevado significativo de variáveis (STONE, 2011).

Para Stone (2011), apesar da importante contribuição, ambas as correntes possuem problemas e limitações. No caso da perspectiva elitista, profundamente marcada pela descrença na 
democracia, não considera a importância dos "grupos populares" e tão menos seu papel social como relevante. Porém, pelo fato de retratar grupos restritos, as minorias no poder, pode lançar mão de um conhecimento detalhado sobre os atores investigados. Já o estudo das massas acaba se valendo de recortes do grupo social, ou seja, corre riscos com as amostras aleatórias, mas pode representar, muitas vezes, de fato o grupo que se pretende elucidar.

Um dos traços averiguados para detectar o perfil parlamentar do referido período diz respeito à idade dos deputados quando da entrada na ALEP. Nesse sentido, a idade média ${ }^{13}$ dos parlamentares corresponde a 39,53 anos. Desse modo, destaca-se que o corpo parlamentar foi formado por membros relativamente jovens. Dentre eles, o deputado que ingressou na ALEP com maior idade foi Francisco Silveira da Rocha, (PTB, negociante de café em Marialva), com 71 anos. Já a idade mais jovem detectada foi de 27 anos, identificada nos seguintes deputados: Lincoln Ferreira da Cunha Pereira (PSP, advogado e secretário do Trabalho e Assistência Social) e Francisco Accioly da Costa Filho (PSD, delegado civil, professor, deputado federal e senador) ambos vinculados a famílias com capitais políticos importantes, Linneu Madureira Novaes (PSD, médico em Piraí e Castro); além de Léo de Almeida Neves (PTB, economista, advogado e jornalista, foi deputado federal e diretor do Banco do Brasil), que assumiu seu mandato como suplente aos 26 anos de idade.

A presença dos deputados na ALEP, a partir da trajetória de cada um no que diz respeito ao número de legislaturas, destaca-se como critério relevante para compreensão da carreira parlamentar (DOMINGUES, 2001), assim como também enfatiza a distribuição dos mandatos em relação aos deputados. Nesse caso, a concentração de parlamentares ocorreu na participação de apenas uma legislatura, ou seja, dos 126 deputados do período, 64 parlamentares tiveram apenas um mandato na ALEP (ver Quadro 1).

13 Dos 126 deputados do período, apenas a idade de oito deputados não foi identificada nas diversas fontes de busca. Portanto, para a análise considerou-se o grupo de 118 membros. 
Quadro 1 - Presença Parlamentar

\begin{tabular}{|c|c|c|}
\hline $\begin{array}{c}\text { Número de } \\
\text { Legislaturas }\end{array}$ & Número de deputados & $\%$ \\
\hline 1 Leg. & 64 & 50,79 \\
\hline 2 Leg. & 29 & 23,01 \\
\hline 3 Leg. & 23 & 18,25 \\
\hline 4 Leg. & 5 & 3,96 \\
\hline 5 Leg. & - & 3,17 \\
\hline 6 Leg. & - & - \\
\hline 7 Leg. & - & - \\
\hline 8 Leg. & 1 & 0,79 \\
\hline 9 Leg. & & \\
\hline
\end{tabular}

Fonte: A Autora.

Nota: Construído a partir de NÍCOLAS, 1984; IPARDES, 1987.

Contudo, a maior concentração de capital político no interior da ALEP e ao mesmo tempo em termos de presença parlamentar é o caso de Aníbal Khury, comerciante e ex-vereador em União da Vitória (1955-1958, 1959-1962, 1963-1966, 1967-1970, 1983-1986, 1987-1990, 1991-1994, 1995-1998 e 1999), que direcionou em sua carreira para a Assembleia Legislativa, ocupando nove legislaturas, ou seja, 36 anos de ALEP (os cargos e comissões ainda serão averiguados). Vale ressaltar que para a análise não se delimitou o período estudado na ocupação das legislaturas, mas procurou-se verificar a capacidade do parlamentar de se estabelecer na instituição e angariar capitais para que sua presença fosse mais extensa temporariamente. Os demais com várias legislaturas, cinco, compreendem deputados com capitais políticos e econômicos também relevantes: Amadeu Puppi, UDN, médico, vereador e vice-prefeito em Ponta Grossa (1951-1954, 1955-1958, 1959-1952, 1963-1966, 1967-1970 suplente); Antonio Anibelli (1951-1954, 1955-1958, 1959-1962, 1967-1970, 197101974); Domício Scaramella, PTB, comerciante, empresário do setor madeireiro e ex-prefeito em União da Vitória (1955-1958, 1959-1962, 1970-1973, 1974-1977, 1978-198014); e João Mansur, PSD e PDC, comerciante e madeireiro, ex-prefeito em Irati (19591962, 1963-1966, 1967-1970, 1971-1974, 1978-1982).

Outro fator interessante para avaliação dos legisladores do referido período é a composição de origem dos deputados haja vista que no contexto da República Velha havia uma concentração (GOULART, 2014) efetiva do chamado Paraná tradicional (Litoral, Curitiba e Campos Gerias), ao passo que no período posterior a distribuição ainda não ocorre com forte presença de representantes

\footnotetext{
${ }^{14}$ Faleceu em 1980, antes do encerramento do mandato parlamentar.
} 
do norte do paranaense. Contudo, observa-se a presença significativa de 31 deputados provindos de outros estados: 11 de São Paulo, 2 da Bahia, 7 de Minas Gerais, 4 do Rio de Janeiro, 6 do Rio Grande do Sul e 1 de Santa Catarina. Vale ressaltar o caso de Rosy de Macedo Pinheiro Lima (advogada), primeira mulher a ocupar cadeira na ALEP, nasceu na França, mas representa seus familiares ligados ao Paraná tradicional. (GOULART, 2916)

\section{CONSIDERAÇÕES FINAIS}

Os estudos sobre o poder legislativo tornam-se cada vez mais importantes, pois são subcampos políticos fundamentais para análise do real desenvolvimento democrático e podem, conjuntamente, indicar as lacunas a serem compreendidas e superadas. Dessa forma, tomando-se como objeto de estudo a ALEP, tem-se como intuito refletir acerca da dinâmica do poder presente em uma das instituições mais significativas em termos de representação política. Analisar o subcampo parlamentar a partir de sua dinâmica de funcionamento e do perfil de seus integrantes permite-se averiguar os caminhos que o processo legislativo ainda precisa percorrer para que alcance verdadeira representatividade social.

Em se tratando do objeto ainda em estudo, a ALEP de 1947 a 1962 e seus 126 representantes, abre-se possibilidade para compreensão mais ampla da política e dos políticos paranaenses do período, assim como também de se conhecer o parlamento atual por meio dos vínculos estabelecidos por seus parentes ainda no passado. Mesmo que não apresentado todos os aspectos e critérios para definição do perfil parlamentar, infere-se que cerca de metade de seus membros tiveram pouca expressão política nesse campo de poder.

A presente abordagem identificou que $50,47 \%$ dos deputados cumpriram um mandato político no referido subcampo, a concentração de poucos indivíduos com grande presença revela que o poder parlamentar ficou restrito ao grupo dominante, vinculado a famílias de tradição política no Paraná. Conquanto, a forte presença de famílias advindas de uma história política de longa duração faz com que se reflita em torno dos mecanismos de poder utilizados para sua sustentação, tema que será abordado no próximo trabalho. 


\section{REFERÊNCIAS}

BATISTELLA, Alessandro. O sistema pluripartidário de 1945-1965 no Paraná: uma análise dos Partidos Políticos, Governadores e das eleições no estado. Tempos Históricos, v. 19, p. 111-150, 2015.

BOURDIEU, Pierre. O poder simbólico. 5. ed. Rio de Janeiro: Bertrand Brasil, 2002.

Os usos sociais da ciência: por uma sociologia do campo científico. São Paulo: Ed. UNESP, 2004.

CANEDO, Letícia Bicalho. Caminhos da Memória: parentesco e poder. Revista Textos de História, Brasília, v. 2, n. 3, p. 85-122, 1994.

Ritos, símbolos e alegorias no exercício profissional da política. In: CANÊDO, Letícia Bicalho. (Org.). O sufrágio universal e a invenção democrática. São Paulo: Estação Liberdade, 2005.

Um capital político multiplicado no trabalho genealógico. Revista Pós Ciências Sociais, Maranhão, v. 8, n. 15, p. 55-75, jan./jun. 2011.

CONSTITUIÇÃO POLÍTICA DO ESTADO DO PARANÁ. 1947. In: FANCKIN, Reginaldo. Sistema Constitucional do Paraná: contribuição à história política do estado. Curitiba: Poder Legislativo, 1974.

COSTA, Samuel G. da. História Política da Assembleia Legislativa do Paraná. 2. V. Curitiba: Assembleia Legislativa, 1995.

DOMINGUES, M. P. Espírito Santo: produção legal e relações entre os poderes Executivo e Legislativo entre 1995 a 1998. In: SANTOS, F. (Org.). O Poder Legislativo nos Estados: diversidade e convergência. Rio de Janeiro: FGV, 2001.

FREIRE, Gilberto. Casa Grande \& Senzala. Edição Comemorativa dos 80 Anos. São Paulo: Editora Global, 2013.

GOULART, Mônica Helena Harrich Silva. A Dança das Cadeiras: análise do jogo político na Assembleia Legislativa do Paraná (1889-1930). Jundiaí, SP: Paco Editorial, 2014.

. Classe Dominante e Jogo Político na Assembleia Legislativa Paranaense (1889-1930). Tese (Sociologia). Universidade Federal do Paraná - 609 f. Curitiba, 2008.

As Mulheres na ALEP: uma abordagem prosopográfica. In: OLIVEIRA, Ricardo Costa de. (ORG.). Nepotismo, Parentesco e Mulheres. Porto Alegre: RM Editora, 2016.

GRANATO. Natália Cristina. O campo político paranaense no contexto do Golpe de 1964 e suas lutas políticas. Dissertação (Sociologia). Universidade Federal do Paraná - 272 f. Curitiba, 2016. 
GRILL, Igor Gastal. "Famílias", ascensão social e alinhamentos partidários no Rio Grande do Sul. Revista de Ciências Sociais, Fortaleza, v. 43, n. 2, p. 137-157, jul./dez. 2012.

HOLANDA, Sérgio Buarque de. Raízes do Brasil. 26 ed. São Paulo: Companhia das Letras, 1995.

IPARDES. Resultados Eleitorais no Paraná: 1945-1982. Curitiba: IPARDES, 1987.

MAINWARING, S. P. Sistemas partidários em novas democracias: o caso do Brasil. Porto Alegre: Mercado Aberto; Rio de Janeiro: FGV, 2001.

MARTINS, Carlos Benedito. Revista Brasileira de Ciências Sociais, São Paulo, n. 26, ano 9, out. p. 179-181, 1994. Resenha de: BOURDIEU, Pierre; WACQUANT, Loic. Réponses: pour une antropologie réflexive. Paris: Editions du Seuil, 1992.

NÍCOLAS, Maria. 130 Anos de Vida Parlamentar Paranaense 1854-1984. Curitiba: Setor de Editoração e Publicações da Coordenadoria de Estudos e Promoções Especiais, 1984.

OLIVEIRA, Ricardo Costa de. Na Teia do Nepotismo: sociologia política das relações de parentesco e poder político no Paraná e no Brasil. Curitiba: Ed. Insight, 2012.

Notas sobre a política paranaense no período de 1930 a 1945. In: OLIVEIRA, Ricardo Costa de; SALLES, Jefferson de Oliveira; KUNHAVALIK, José Pedro. A Construção do Paraná Moderno: políticos e política no Governo do Paraná de 1930 a 1980. Curitiba: SETI, 2004.

O Silêncio dos Vencedores: genealogia, classe dominante e Estado no Paraná. Curitiba: Moinho do Verbo, 2001.

STONE, Lawrence. Prosopografia. Revista de Sociologia e Política, Curitiba, v.19, n. 39, p. 115137, jun, 2011.

VIANNA, Oliveira. Instituições Políticas Brasileiras. 2. V. São Paulo: Editora UFF, 1987.

\title{
POLITICAL POWER AND FAMILY IN ALEP: 1947-1962
}

\begin{abstract}
This text is an analysis (in progress) on the concentration of power and kinship relations in the Legislative Assembly of Paraná, in the period from 1947 to 1962 . This parliament is understood in this sense as a subfield of Paraná political field, as research possibilities from Bourdieu's perspective. The political trajectories and biographies of the deputies are relevant to understanding the concentration of power and kinship relations set in that area. Dictionaries and biographical works, texts on legislative and policy Paraná, in addition to official and specific sites, are used as important sources for research.
\end{abstract}

Key-words: ALEP. Paranaense policy. Family. 